\title{
Managements' perspective on Canadian public health nurses' primary health care practice
}

Donna M. Meagher-Stewart and Megan L. Aston School of Nursing, Dalhousie University, Nova Scotia, Canada, Nancy C. Edwards School of Nursing, University of Ottawa, Ottawa, Canada, Linda Young Public Health Services, Capital District Health Authority, Nova Scotia, Canada and Donna Smith South Shore District Health Authority, Nova Scotia, Canada

\begin{abstract}
An interpretive qualitative study was conducted to examine public health nurses' (PHNs') practice in fostering citizen participation and collaborative practice and the impact of a decade (1992-2002) of health care restructuring. This article presents the perspectives of public health management and a public policy analysis as they relate to PHNs' primary health care practice in Nova Scotia, a province in Eastern Canada. Seven face-to-face interviews were conducted with public health management from across Nova Scotia and 26 relevant public policy documents were analyzed. Three major themes emerged from the coded transcripts and the document analysis: (1) opportunistic shifts in values: constraining structures, operations, and governance; (2) insufficient funding and infrastructure support; (3) opportunities and challenges to PHN capacity and competency. The emergent themes illustrate the unique population health perspective and day-to-day contested realities of public health and PHN practice. The study provides preliminary understanding of $\mathrm{PHNs}^{\prime}$ primary health care practice in Nova Scotia that may resonate with other national and international settings. This knowledge can form a basis for more research to explore the PHNs' practice in the organizational context in which it is embedded. This study was undertaken at a pivotal time in Nova Scotia as the provincial government embarked on primary health care renewal to improve the health of Nova Scotians. The success of this study is in large part attributable to the collaborative effort of university researchers and public health decision makers.
\end{abstract}

Key words: Canada; citizen participation; collaboration; community-based research; nurses; primary health care; public health; public health management

Received: August 2006; accepted: January 2007

\section{Introduction}

Publicly-funded public health is integral to Canada's health care system, with its focus on population health assessment, health surveillance, health promotion, disease and injury prevention, health protection (Federal, Provincial, Territorial Advisory

Address for correspondence: Dr Donna Meagher-Stewart, Room N19, School of Nursing, Dalhousie University, 5869 University Avenue, Halifax, Nova Scotia, Canada B3H 3V2. Email: donna.meagher-stewart@dal.ca
Committee on Population Health, 1999), and the delivery of primary health care (Community Health Nurses Association of Canada (CHNAC, 2003). Inquiries into the Canadian public health system describe challenges and opportunities for capacity enhancement (Romanow, 2002; Naylor, 2003; Standing Senate Committee on Social Affairs, Science and Technology (Kirby Report, 2003). The West Nile Virus, tainted water, BSE-Mad Cow, and SARS have brought attention to the Canadian public health system's decreased capacity to respond to urgent and prolonged crises with resources already 
stretched to the limit (Sullivan, 2002; Canadian Institute of Health Research, 2003; Canadian Public Health Association, 2003; Frank and DiRuggiero, 2003; Frank et al., 2003). Calls for additional resources, nationally-coordinated public health, and a clarification of professional standards are increasingly evident (Kluge, 1999; Frank and DiRuggiero, 2003 Frank et al., 2003). In partial response to these calls, the Public Health Agency of Canada was established in 2004 (Kiefer et al., 2005).

Canada consists of 10 provinces and three territories, which have constitutional jurisdiction over most of health care. Health Canada, the federal department, enforces health regulations, provides strategic direction on national health policies, supports healthy living for Canadians, and is responsible for First Nation and Inuit health care, health surveillance, and product safety systems. 'Canada has 13 different public health systems. The provinces and territories are not bound by legislated principles in the same way that the Canada Health Act supports hospitals and medical care across the country. This arrangement makes it difficult to make generalizations about the overall public health function in Canada.' (Kothari and Edwards, 2003, p. 393). One of the most significant restructuring changes in Canada's health care system has been the move to regionalization, which has been occurring for 20 years, and involves decentralizing authority from the provincial government to regional health authorities (Braunstein et al., 2000). This study was undertaken to explore PHNs' primary health care practice in light of substantial health care reorganization and policy changes.

\section{Study setting}

The study was conducted in the province of Nova Scotia. This is a small province with a population of less than one million residents (Statistics Canada, 2005). In 2001, the health services in the province were decentralized. Nine District Health Authorities (DHAs) were established with 37 community health boards reporting to the DHAs and four Public Health Service areas (Nova Scotia Department of Health (NSDOH, 2000). Three of the more rural Public Health Service areas participate in a Shared Service Area (SSA) model and as such are part of up to three different DHAs. The SSA model is unique in Canada to Nova Scotia. It was put in place to allow Public Health Services to have a sufficient critical mass of population and staff to address their public health mandate (Moloughney, 2006). The nine DHAs include populations ranging from 32711 to 402094 (NSDOH, 2005). At the inception of this study, practitioners and management (henceforth referred to as managers) in Public Health Services expressed concern that such structural and accountability changes as regionalization and budgetary constraint were compromising public health capacity and services.

PHNs account for the greatest proportion of the public health workforce in Canada (Naylor, 2003). They engage in the specialty practice of community health nur-sing that is informed by nursing and public health sciences and the principles of primary health care, health promotion, community empowerment, and population health (CHNAC, 2003). They are major contributors to primary health care (Rodger and Gallagher, 2000). PHNs' are accountable to the public, to the nursing regulatory body, and to the employer, and are governed by provincial legislative and policy mandates.

Although there is a growing body of Canadian and international research on PHNs' primary health care practice, less research has described how PHNs foster citizen participation and engage in collaborative practice (Rodger and Gallagher, 2000). A review of international literature concluded that the roles and issues faced by nurses in primary health care are poorly understood and require further careful examination (Health Canada, 2000).

While PHNs have delivered primary health care programmes and services in Nova Scotia for many years, there has been minimal evaluation of these programmes and no known research has been conducted to examine the impact of public sector changes on PHN practice in Nova Scotia.

In September 2001, Nova Scotia followed the federal government's lead by embarking on primary health care renewal to improve the health of Nova Scotians, who are among the unhealthiest citizens in Canada (Canadian Institute of Health Information, 2000; Colman, 2003). Key strategies in this mandate, included building on successful elements already in place (such as PHNs) and fostering an improved, integrated, and communitybased health care system, were particularly relevant to this inquiry. This article reports the first phase of an interpretive qualitative study conducted from November 2002-March 2005 that

Primary Health Care Research \& Development 2007; 8: 170-182 
examined the contextual and relational practice knowledge of PHNs, particularly how they foster citizen participation and engage in collaborative practice in the context of health care restructuring in Nova Scotia (Meagher-Stewart et al., 2004). In phase one (January-April 2003) public health managers were interviewed and applicable public policy and budgetary decisions between 1992 and 2002 were analysed. This period was a time of significant health care restructuring. Phase two and three (March 2003-September 2004) consisted of individual interviews $(n=44)$ with PHNs followed by focus group interviews with PHNs $(n=31 \mathrm{PHNs})$.

\section{Methods}

This interpretive qualitative study (Drucker, 1999) valued the participants as experts and viewed them, their public health experience, and their perceptions as the starting point for analyzing how their work situation is shaped by and in turn, shapes their social world (Smith, 1987; Hall and Stevens, 1991; Bloom 1998). This inquiry process guided data collection and enabled an in-depth perspective on the history, gender, and social relations of PHN practice through public health managers' voices and document analysis. A partnership between university researchers and public health decision makers was critical to this study's success.

\section{Recruitment and data collection procedures}

Ethical approval was obtained from Dalhousie University's Ethics Board and Nova Scotia's nine DHAs. Eligible participants were identified by the investigative team as having held their positions for five years at the time of the study, and currently working for either the Nova Scotia Department of Health or one of the four Public Health Service areas in the DHAs. Due to time and funding limitations, not all eligible managers could be interviewed. Random sampling (Patton, 2002) was used to select public health managers from a roster of eligible participants $(n=12)$. This sampling technique gave all of the eligible participants an equal chance of being selected, thereby reducing suspicions as to why some individuals were selected and not others. Participants were contacted by letter and Primary Health Care Research \& Development 2007; 8: 170-182 gave informed consent to participate in an interview.

An interview guide was developed by the research team. The semi-structured interview was first piloted with an experienced PHN. One individual, face-to-face, interview (approximately 90 minutes) was conducted with each participant. Participants were asked to share their perspectives on:

- how PHNs' foster citizen participation and collaborative practice

- facilitators and barriers to fostering citizen participation and collaborative practice

- the impact of federal, provincial, and DHA policy and funding decisions on public health programmes, services, and leadership, as well as on PHNs' partnerships with citizens and collaboration at inter-professional and inter-sectorial levels.

The questions allowed the participants to address the issues from their managerial position and experience. Interviews were audio-taped, transcribed, and sent to participants. Follow-up telephone interviews (approximately 20-30 minutes) two to three weeks later allowed for verification and elaboration of transcript content, as well as discussion of initial findings and interpretations.

The investigative team identified 26 documents that described federal, provincial, and DHA public policy and budgetary decisions pertinent to public health and PHNs' practice in Nova Scotia between 1992 and 2002.

\section{Data analysis}

Transcribed interviews were analysed using established procedures for thematic analysis (Lincoln and Guba, 1985; Miles and Huberman, 1994; Sandelowski, 1995; Kvale, 1996), coding, organizing the data into broad categories, and developing interpretive themes. The principal investigators independently coded the seven interviews, identified emergent themes, and arrived at the final coding and thematic structure by consensus. Documents were examined chronologically for historical, philosophical, and structural context. A research assistant completed the document analysis. Explicit references to the roles of PHNs were extracted from the documents. Coded transcripts were compared to findings from the document analysis to confirm similarities and differences, and to identify and corroborate themes related to 
the social, economic, and political context of the PHNs' everyday practice.

\section{Establishing rigour}

Several strategies were used to establish a rigorous research process with credible findings (Lincoln and Guba, 1985; Hall and Stevens, 1991): random sampling, member checking through telephone follow-up interviews, and in-depth descriptions from a representative number of public health managers across a variety of positions at the provincial and DHA levels.

\section{Results}

The sample consisted of seven senior public health managers, three from the Nova Scotia Department of Health, and four from each of the Public Health Service areas in the DHAs in Nova Scotia. Participants had 12-30 years of public health experience $(\bar{x}=21) ; 8-17$ years of experience in public health management $(\bar{x}=13)$; and $2-16$ years in their current position $(\bar{x}=8)$. The sample represented various disciplines: nursing $(n=5)$, public administration $(n=1)$, and community medicine (1).

Three major themes emerged from an integration of the public health interview data and the document analysis: (1) opportunistic shifts in values: constraining structures, operations, and governance, (2) insufficient funding and infrastructure support, and (3) opportunities and challenges to PHN capacity and competency.

\section{(1) Opportunistic shifts in values: constraining structures, operations, and governance}

This theme reflects the tension between participants' expressed value orientations and increased expectations by the federal, provincial, and DHA levels of government towards population health and primary health care. In reality, public health capacity has been compromised in its population health and primary health care functions due to constraining structures, operations, and governance. The changes that took place between 1992 and 2002 created a need for new knowledge and skills and more organizational support at the provincial, regional and community levels as well as role and responsibility definition.

Three sub-themes were also identified within this category: (a) validation of public health; (b) environment of constant change, restructuring, and erosion of public health capacity; and (c) paradox of regionalization.

\section{Validation of public health}

Participants described 24 federal and 40 provincial initiatives that directly influenced public health programming in the previous decade. In particular, they noted that the emphasis on population health and primary health care renewal reinforced the historical leadership role of public health.

As one participant commented,

P1: I think population health has validated the way public health is practised ... We normally would look at an individual, a community, a population in a very holistic way ... I think someone at the provincial level and the federal level are [sic] actually saying 'Yes, that's the right way to be practising.'

Primary health care renewal was seen as potentially increasing the visibility of PHNs' collaborative, community practice, as well as increasing opportunities for partnerships. However, as the following participant's quote indicates, primary health care renewal will only happen with the necessary infrastructure support.

P5: We are looking at what sorts of supports in the renewed primary health care system there will be for public health, primary prevention and population health to advance inter-sectorally and what sorts of infrastructure and systems do we need to change.

\section{Environment of constant change, restructuring, and erosion of public health capacity}

Document analysis and participant accounts acknowledged that the ongoing restructuring of Nova Scotia's public health system since the early nineties resulted in a number of policy and governance changes (Table 1) that contributed significantly to the erosion of public health's capacity. The loss of senior public health management at decisionmaking tables, loss of health inspectors from the public health team, and major shifts in accountability for public health at provincial and regional levels

Primary Health Care Research \& Development 2007; 8: 170-182 
Table 1 Notable changes that significantly affected public health capacity in Nova Scotia

- Shift in 1997 of Public Health Services accountability
and reporting from the Department of Health to four
Regional Health Boards (Nova Scotia Department of
Health Blueprint for Health Care Reform Committee,
1994)
- Decentralization in 2001 to nine DHAs with 37
Community Health Boards (reporting to the DHAs) and
four Public Health Service areas (NSDOH, 2000)
- Nova Scotia population of 937,000 residents
(Statistics Canada, 2005) spanning nine DHAs with a
population range of 32,711 to 402,094 (NSDOH,
2005)
- Creation of a Shared Service Model for three Public
Health Services spanning eight DHAs
- Public health inspectors transferred from the
Department of Health to other government depart-
ments in the early nineties
- Loss of the Director of Public Health position in 2001
Legislated accountability for health protection and
communicable disease in the office of the Chief
Medical Officer of Health in 2001, who does not have a
direct connection to Public Health Services (NSDOH,
2000)
- Medical Officers of Health in the DHAs assigned a con-
sultant role with Public Health Services (NSDOH, 2000)
Accountability for health promotion, health enhance-
ment, and population health divided between the
Department of Health's Population Health Unit, and a
new Office of Health Promotion (NSDOH, 2003)

were viewed as being particularly detrimental to public health capacity. Despite emerging Health Canada funding opportunities and provincial structural changes that offered the possibility of strengthening public health, health system reorganization and lack of provincial political leadership undermined and eroded public health capacity and PHN practice. The following comment illustrates how the provincial government's removal of traditional public health programmes from their mandate, constant change, and reorganization were viewed as eroding public health capacity.

P1: The issues we had 8-10 years ago are still the issues today. Why haven't we been able to improve on some of them? I think part of it is the structure ... we have public health further down the food chain reporting to the [Director of Population Health]. We have separated out tobacco, we have separated out AIDS, primary health care. So people don't have a consistent picture and it is difficult to move your way up the decision making path.
Removing public health to districts and regional health boards was not a good one. Now we have some commitment to move on public health at the provincial level. Not sure about the district level.

Participants considered the provincial government's lack of leadership in public health matters an important factor contributing to public health's eroding viability.

P6: We need [political] leadership and ownership at the provincial level before we can access what is available federally. If you don't have ownership you will probably not even pursue funding. It costs, so it has to be a priority. In having the responder mentality, they [provincial government] do not have the sustainability when the funding runs out.

This comment indicates how the lack of provincial leadership was seen to affect PHN practice.

P7: There are many things we need to do difficult to do on dwindling resources. Very frustrating for public health nurses who value these programmes ... When they see it prioritized away - they see it not valued. All of this is to say someone, provincially, has to take some leadership and some bit of money has to go to this population [client].

\section{Paradox of regionalisation}

Participants initially viewed the new regional DHA structure as an opportunity to promote a more integrated, community-based system, stronger partnerships for public participation, and a more expedited structure for local decision making. However, this did not translate into practice. Working in the DHA structure was described as 'cumbersome', a 'dance', a 'painful process', and a 'pull and tug'. This was particularly the experience in SSAs, which were more rural, where Directors of Public Health Services were accountable to two or three CEOs, Vice Presidents, and DHA Board Chairs. Under the DHA structure much time and energy were required to create and maintain strong partnerships and to have public health understood. Public health managers were sometimes caught in a power struggle between provincial and DHA 'primarily acute care ... institutional-based' systems. Participants noted that their voice was extremely 
compromised and they became 'an even smaller fish in a bigger pond' at a time when public health should play a leadership role in the population and primary health care agenda. To illustrate,

P4: It has been a challenge. The [public health] services that we provide fit better as a region ... The staffing in public health is very small. If you had them managed by the district that would be a very small staff. It has always been a challenge; each district is looking at their interests. We remained a 'Shared Service'. We report to three VPs who report to three CEOs. Is difficult sometimes because we have that [governance structure]. The districts are now our employers; however we get policies and direction from the province. It is more cumbersome now for us. In a way I'm glad that the funding was kept provincially, that way we maintain our standards and districts can't opt out of it. Trying to get the VPs to understand what we do in public health is a challenge.

Public health managers felt that they were continually justifying their existence because of the lack of understanding and valuing of Public Health Services. As one participant stated,

P6: You are constantly justifying who you are and what you are doing to a system that is basically functioning on a medical illness model. They [DHA Board] recognize the task things - immunization, delivery of programmes (one-on-one) to post-partum mothers - they do not recognize the vague policy or the influence public health has around prevention issues, around the valuing of population health.

\section{(2) Insufficient funding and infrastructure support}

This second major theme captures the conditions and challenges around the perceived lack of federal and provincial government investment in Nova Scotia's public health infrastructure as revealed through document analysis and managers' accounts. Two sub-themes were evident: (a) tensions related to Health Canada's programmes and funding; and (b) insufficient infrastructure support.
Tensions related to Health Canada's programmes and funding

Although the public health managers welcomed Health Canada funding (administered both through regional and national offices), the infusion of funds often shifted public health's strategic directions, leading to a clustering of programmes and staffing around Health Canada priorities. Furthermore, public health often lacked core funding to sustain programmes after Health Canada funding ceased. Other community partners received Health Canada funding and took the lead on programmes with roots in public health. This was happening when public health was receiving less provincial funding, yet trying to meet increasing demands of the province, DHAs, and community partners. The lack of direct Health Canada funding for public health, and the unsustainable nature of the funding were perceived by management as devaluing public health and key factors in public health fragmentation in Nova Scotia.

P7: Health Canada puts in their contract that you must have a contract with the local public health district unit. This puts the responsibility on public health to make something work but we have no control over the dollars or how it works. These are federal dollars funded directly into the province, past provincial government, down to an organization. The link becomes between that initiative and the local public health unit. It is a negotiated partnership. I feel we spend a lot of time chasing the money. In my area there have probably been ten initiatives over ten years that were directly related to fundamental public health issues for which some other group or agency got the money. Then the public health unit had to work in partnership with that agency to achieve what is the public health mandate.

\section{Insufficient infrastructure support}

Historically, public health has been poorly resourced provincially, with little investment in public health infrastructure. This situation was further exacerbated in the mid-' 90 s by decreased federal government transfer payments to the provinces for health care, coupled with block funding to health, education, and community services. These federal funding changes resulted in fewer public health resources.

Primary Health Care Research \& Development 2007; 8: 170-182 
Insufficient provincial funding and staffing presented challenges for Public Health Services in many areas including health surveillance and responsiveness to government directives on social determinants of health. Standards and outcomes for public health programmes were developed in 1997 (NSDOH, April 1997). However, there was a lack of data about Public Health Services and a lack of analysis of infrastructure at the DHA level, making it difficult to demonstrate the value of public health to DHAs.

$\mathrm{P} 1$ : I think the negative thing is we never really tied the funding to programmes, standards and targets. We have this mix of we know we need public health nurses and nutritionists and dental hygienists to accomplish this particular target, but we never said this is going to cost us this much.

Participants acknowledged that insufficient funding for Public Health Services was further compromised by DHA reorganization and increased funding demands from all health care system sectors. As demonstrated by the following comment,

P3: Public health funding is meant to be core funding which was non-transferable and therefore should be there. But in order to move the agenda forward we need more resources. Where are you going to get the resources from...districts need to do it and districts vary in the degree to which they are funding various things. That is part of their system. That is an issue.

As there was very limited funding for public health, participants were adamant that protected block funding for Public Health Services in the DHA structure needed to be retained. As the following comment illustrates, participants believed that restructuring to a DHA structure and the devolution of the Department of Health away from direct service might be a positive thing in the long run, but a 'painful' process to go through when restructuring was happening concurrent with financial constraints.

P7: In the day-to-day piece it is difficult to see the positive aspects. The devolution of government out of direct services and toward a focus on a policy level where they should be, has sometimes felt like a two step dance; two steps forward and one back. Sometimes one step forward and two back ... while restructuring was happening, the financial restrictions were taking place. So we had a massive shift from an acute care, clinical, medical focus to a community-based focus. In the long run it is a good thing. But, it has been painful ... public health has less than $2 \%$ of health funding dollars. Yet, it is the public health piece that is expected to give the evidence or inform the process on why you need to change, and how change will have a positive influence on your health status. So your public health unit should be giving the upstream evidence; here is an emerging problem for which we need to develop strategy to make a difference. I don't think that has happened very well.

\section{(3) Opportunities and challenges to public health nurses' capacity and competency}

The third major theme addresses $\mathrm{PHN}$ practice and public policy and the influence of public health nursing funding decisions. Two sub-themes were identified: validation and reinforcement of PHNs' capacity and competency; and increased expectations and lack of role clarity.

\section{Validation and reinforcement of PHNs' capacity and competency}

The managers felt strongly that PHNs make a difference in the health of the community. They recounted numerous examples of their skills in population health and collaborative practice, particularly in rural communities. The managers noted that PHNs were increasingly asked to bring their expertise and leadership skills (eg, evidence-based planning, application of community development approaches, working with vulnerable and rural populations) to primary health care initiatives undertaken with local partners.

P5: They [PHNs] ... advocate on behalf of communities ... advocate for healthy public policy ... and a population health focus-helping communities interpret what some of the research has said, what the findings have been, getting them to help people understand what a particular stat means, or why is only a certain percentage of population accessing services. The public health nurses have provided leadership in that area. 
In one particular instance, PHNs expertise was acknowledged when Health Canada provided funds through the national Early Childhood Initiative Program. This program enabled more PHNs to be hired to work in collaboration with lay home visitors as part of an Enhanced Home Visiting Program for new mothers in families 'at risk'.

Yet, the participants emphasized that significant tensions and constraints compromise PHNs' capacity and competency and managements' public health leadership. One participant aptly described the overall approach of management in the midst of the many disruptions associated with health care restructuring from 1992-2002 - 'keep their head down and keep going.'

Participants described many strategies to reinforce the strengths of the PHN workforce and to reinforce the importance of Public Health Services, such as: continuing education, mentorship programmes, working alongside PHNs on public health policy, developing and implementing standards for public health, using systematic reviews, and communicating public health priorities to DHAs.

\section{Increased expectations and lack of role clarity.}

Participants highlighted many roles and job descriptions for PHNs, some reflecting increased specialization, others a wider range of responsibilities within a generalist practice model. However, the document review yielded a more ambiguous picture. The roles of PHNs were not specified in the 26 documents reviewed, with one exception, the Nova Scotia Health Standards (NSDOH, April 1997). In contrast, the Act to Provide for Community Health Boards and District Health Authorities (NSDOH, 2000) defined community-based health services, the parameters for DHAs, and the 37 Community Health Boards in Nova Scotia. The Act holds significant implications for Public Health Services and public health professionals, yet these constituents are not named.

Participants described how regionalization, multiple obligations, increased role blurring, and general lack of understanding of public health nursing required more role clarification, negotiation, and justification by PHNs with other professionals. In some instances, the managers described how PHNs increased their involvement in collaborative community projects while continuing to carry out their mandatory programmes. As a consequence, they had a reduced presence at provincial planning tables and reduced visibility. They also explained that with more focused programmes (eg, school health, family health, communicable disease control) and with the DHA as the PHNs' employer rather than the province, there were fewer opportunities for communication among PHNs across programmes and DHAs. Participants also expressed concern that with PHNs pulled in different directions with multiple programmes and expectations, time constraints often made it difficult for them to make a significant contribution to one project. Therefore, PHNs were primarily involved in getting projects started and then stepping back.

As the complexity of the nurses' practice increased, documentation remained task-oriented, misunderstanding of PHNs' scope of practice grew, and they experienced less control of their practice. The following comment illustrates some rationale for the misperceptions of the PHNs' specialty practice.

P2: Public health always worked on a decentralized model. It's not working as well as people thought it would. We've had difficulty communicating the scope, competencies, and practice of public health nursing. If you think it takes four years to learn to be a nurse, people think they can understand public health nursing in half an hour, or a 2-day workshop, and therefore they believe they are entitled to make decisions, and decide what nurses should and should not be doing. It is not medicine, it's its own body of knowledge, but people have difficulty articulating that public health nursing is a specialty.

Nova Scotia is the size of one health unit in other places, so public health could be managed as one entity. Now we have different levels of competency of public health nurses. There's a move in some districts to almost make public health invisible and integrate public health nursing into other kinds of nursing and health promotion kinds of things. That to me represents lack of understanding of the very special knowledge that is brought to bear.

With public health manpower scarce, the managers described the dilemma of decreased contact

Primary Health Care Research \& Development 2007; 8: 170-182 
with the community in general, and with vulnerable and rural populations in particular, contributing to an increasingly dissatisfied and invisible PHN workforce.

P7: The public health nurse has limited funding or time to do the direct service piece. Then, she has to take that time to do more partnering and community/committee work. That has benefits because you get to know your agencies and their population, but when you don't have the extra resources to go with it, it can detract from some of your [mandatory] work as a public health nurse. Therefore, public health nurses get quite frustrated and stressed by the fact they are so pulled. When you look at the outcomes of these [partner] organizations they look like they are doing a wonderful job, but it never would have happened if the public health nurse was not involved in making a contribution. Yet, there is very little recognition of that.

\section{Discussion}

This study was undertaken at a pivotal time in Canadian health care system renewal. The study revealed that misunderstandings of public health and PHN practice, lack of provincial investment, chronic under funding, and a decade of public health system restructuring (in particular regionalization) compromised public health capacity and PHN practice in Nova Scotia. A growing disconnect emerged between the vision of public health professionals and that of political and bureaucratic leaders. Public health management and PHNs navigated multiple challenges and paradoxes related to policy directives, system infrastructure, and role ambiguity in their endeavours to be effective in their primary health care practice and in building the population health of Nova Scotians.

Nova Scotia spends less on public health than most Canadian provinces (NSDOH, 2002; Naylor, 2003). Indeed, the lack of investment in public health should be of major concern. In October 2004 the Nova Scotia Department of Health and the Offices of Health Promotion requested an external review of Nova Scotia's publicly-funded public health system to assess its capacity, strengths, limitations, and openness to recommendations for a stronger, viable public health system (Moloughney, 2005). The final report (Moloughney, 2006) corroborates our study findings in its identification of factors which impede the public health system including; limited information and knowledge systems; insufficient public health staff who lack graduate level training; complex and cumbersome organizational, governance, and accountability structures; insufficient funding; and a narrowly-defined Health Protection Act.

It is generally acknowledged that regionalization has brought changes in public health governance, leadership, power dynamics, system infrastructure, and visibility, as well as new opportunities for service integration and reorientation to a population focus (Braunstein et al., 2000; Kothari and Edwards, 2003). Various reports have highlighted the challenges and negative impact of regionalization on the Canadian public health system (Sutcliffe et al., 1997; Kluge, 1999; Braunstein et al., 2000; Casebeer et al., 2000; Lewis et al., 2001; Frankish et al., 2002; Kothari and Edwards, 2003; Moloughney, 2005; Jensen and Kisely, 2005), and the need for systematic evaluation of the impact of regionalization (Moloughney, 2006). The public health management participants in this study found themselves caught in the power struggle between provincial and regional systems and within the DHA structure itself, constantly justifying their existence.

Our study findings are consistent with other literature that describes under funding in public health across Canada, highlighting the significant disparities among provinces in their capacity to address public health issues (Sutcliffe et al., 1997; Sullivan, 2002; Frank and Di Ruggiero, 2003; Frank et al., 2003; Naylor, 2003). Numerous tensions that have been noted resonate with our study findings: support for population focused health with no commitment of resources (Sutcliffe et al., 1997); reductions in staff, resources, and salaries (Sullivan, 2002); poor staff retention and ability to replenish resources (Frank and DiRuggiero, 2002; Sullivan, 2002) taking public health for granted, especially in rural areas (Schabas, 2002); and a shift in focus from population health to high risk health (Elliott et al., 2000).

Participants' views concur with Canadian and international literature that suggests that PHNs make a difference in building population health as primary health care practitioners working collaboratively to promote accessibility and citizen 
participation (Rodger and Gallagher, 2000; Meagher-Stewart, 2001; CHNAC, 2003; MacDonald and Schoenfeld, 2003; Underwood, 2003; Clarke, 2004; Keller et al., 2004a; 2004b). The current Canadian nursing crisis calls for a highly skilled workforce and high quality nursing workplaces (Baumann et al., 2001; Health Canada, 2002; Naylor, 2003). Canadian research consistently concludes that the PHN participation and effectiveness in promoting individual and community health is significantly affected by organizational opportunities, support, and resources within workplaces, enabling and constraining it through values, policies, goals, standards, outcomes, and funding availability (Haugh and Laschinger, 1996; Rafael, 1999; Reutter and Ford, 1998; Rafael, 2000; Oberle and Tenove, 2000; Meagher-Stewart, 2001; Krueger et al., 2002; MacDonald and Schoenfeld, 2003; Underwood, 2003). Participants in this study noted that insufficient infrastructure support and the erosion of PHN scope of practice impeded the nurses from being more actively involved in primary health care and practicing to their full potential as PHNs. Similarly, international research has identified a myriad of factors that have adversely affected the PHNs' scope of practice: economic and organizational forces of the US health care system that prioritizes clinical services over population-based activities (SmithBattle et al., 1999; Grumbach et al., 2004); lack of philosophical, organizational, and managerial understanding and commitment to PHN practice (Plews et al., 2000; May et al., 2003; McMurray and Cheater, 2004); authoritative leadership, poor access to information, and short contractual periods of work were found to have a negative effect on community nurses' sense of empowerment (Kuokkanen and Katajisto, 2003); and inequalities in district nursing provisions were found to have a negative impact on service delivery to minority ethnic populations (Gerrish, 1999). The studies revealed how PHNs are constrained in their practice by multiple factors internal and external to their workplace.

\section{Conclusion}

This interpretive qualitative study provides insights into the impact of public policy and budgetary decisions on public health and PHN practice that are consistent with other national and international settings. This knowledge has implications for practice, education, research, and policy as 'the quality of Canada's public health will ultimately rest on the shoulders of public health workers' (Naylor, 2003). Future success in primary health care renewal depends on the ability of public health managers and policy makers to strengthen PHNs' contribution through multiple strategies. Enhanced organizational structures and opportunities are essential for empowering PHNs, promoting work effectiveness, and ultimately improving Nova Scotians' health outcomes. The day-to-day realities of public health practice suggest that the stated value of primary health care and public health nursing need to be translated into public health investments. More opportunities need to be created to make PHNs' innovative practice visible. PHNs' capacity to provide programmes and services is contingent upon the public, other professionals, government officials, and policy makers having a clear understanding and value for their full scope of practice. Funding and other organizational mechanisms need to be mobilized to support: partnerships between university researchers and educators and public health staff; research-based practice and practicebased research; and increased nurse consultant positions. Cross provincial or cross country comparative studies need to be included in future research agendas.

New opportunities, such as the establishment of the Public Health Agency of Canada, a Canadian population and public health evidence centre and research network (Kiefer et al., 2005), an external review of Nova Scotia's public health system (Moloughney, 2006) and the establishment of Canadian standards of practice, competencies, and certification for community health nurses (CHNAC, 2003, 2005) support the timeliness and relevance of these study findings.

\section{Acknowledgements}

Eileen Woodford, research team member; Janet Braunstein-Moody, research collaborator; Lynn Langille, research associate; Anna Jacobs, research coordinator; research assistants: Andrea MacLellan, Janice Acton, Savia Antao, Caroline-Anne Coulombe, Nancy Green; Chris Pauley, research coordinator, School of Nursing, Dalhousie University.

Primary Health Care Research \& Development 2007; 8: 170-182 
Project funding provided by the Nova Scotia Health Research Foundation. Nancy Edwards holds a Nursing Chair funded by the Canadian Health Services Research Foundation, the Canadian Institutes of Health Research and the Government of Ontario. Funding support received from the Atlantic Health Promotion Research Centre.

\section{References}

Baumann, A., O'Brien-Pallas, M., Armstrong Stassen, J., Blythe, R., Bourbonnais, S. and Cameron, D. 2001: Commitment and Care: The benefits of a healthy workplace for nurses, their patients and the system: a policy synthesis. Ottawa, ON: Canadian Health Services Research Foundation.

Bloom, L. 1998: Under the sign of hope: feminist methodology and narrative interpretation. Albany, NY: University of New York Press.

Blueprint for Health Care Reform Committee. 1994: Public health: the invisible partner. Halifax, NS: Nova Scotia Department of Health.

Braunstein, J., Young, H. and Beanlands, H. 2000: Administration in community health nursing. In Stewart, M.J., editor, Community nursing: promoting Canadians' health. Toronto, ON: WB Saunders, pp. 586-99.

Canadian Institute of Health Information. 2000: Statistics. Ottawa, ON: Canadian Institute of Health Information.

Canadian Institute of Health Research. 2003: Proceedings of the 'Think tank on the future of public health in Canada', Calgary, May 10, 2003. Ottawa, ON: Canadian Institute of Health Research - Institute of Population and Public Health.

Canadian Public Health Association. 2003: Public health in public interest; a contribution from the Canadian Public Health Association to the national advisory committee on SARS and public health. Ottawa, ON: Canadian Public Health Association.

Casebeer, A., Scott, C. and Hannah, K. 2000: Transforming a health care system: managing change for community gain. Canadian Journal of Public Health 91, 89-93.

Clarke, J. 2004: Public health nursing in Ireland: a critical overview. Public Health Nursing 21, 191-98.

Colman, R. 2003: Women's health in Atlantic Canada, January 2003 update. Social Determinants of Women's Health. Toronto, ON: Oxford University Press, 17-43.

Community Health Nurses Association of Canada. 2003: Canadian community health nursing standards of practice. Toronto, ON: Community Health Nurses Association of Canada.

Community Health Nurses Association of Canada. May 2005: The first ever certification examination - April, 2006. Community Health Nurses Association of Canada
Newsletter. Toronto, ON: Community Health Nurses Association of Canada.

Drucker, C. 1999: The critique of Heideggerian hermeneutical nursing research. Journal of Advanced Nursing 30, 360-73.

Elliott, S.J., Taylor, S.M., Wilson, K., Robinson, K., Riley, B. and Walker, R. 2000: Restructuring public health in Ontario: implications for heart health promotion. Canadian Journal of Public Health 91, 94-97.

Federal, Provincial, Territorial Advisory Committee on Population Health. 1999: Towards healthy future: second report on the health of Canadians. Ottawa, ON: Health Canada.

Frank, J. and Di Ruggiero, E. 2003: Public health in Canada: what are the real issues? Canadian Journal of Public Health 94, 190-92.

Frank, J., DiRuggiero, E. and Moloughney, B. 2003: The future of public health in Canada: developing a public health system for the 21st Century. Toronto, ON: Canadian Institute for Health Research-Institute for Population Health and Public Health.

Frankish, C.J., Kwan, B., Ratner, P.A., Higgins, J.W. and Larsen, C. 2002: Social and political factors influencing the functioning of regional health boards in British Columbia (Canada). Health Policy 61, 125-51.

Gerrish, L. 1999: Inequalities in service provision: an examination of institutional health influences on the provision of district nursing care to minority ethnic communities. Journal of Advanced Nursing 30,1263-71.

Grumbach, K., Miller, J., Mertz, E. and Finocchio, L. 2004: How much public health in public health nursing practice? Public Health Nursing 21, 266-76.

Hall, J.M. and Stevens, P.E. 1991: Rigor in feminist research. Advances in Nursing Science 13,16-29.

Haugh, E.B. and Laschinger, H.S. 1996: Power and opportunity in public health nursing work environments. Public Health Nursing 13, 42-49.

Health Canada. 2000: Opportunities and potential: a review of international literature on primary health care reform and models. Ottawa, ON: Health Canada.

Health Canada. 2002: Our health, our future: creating quality workplaces for Canadian nurses - Final report of the Canadian nursing advisory committee on health human resources. Ottawa, ON: Health Canada.

Jensen, L. and Kisely, D. March 2005: Public health in Atlantic Canada: a discussion paper. Halifax, NS: Public Health Agency of Canada Atlantic.

Keller, L.O., Strohschein, S., Lia-Hoagberg, B. and Schaffer, M.A. 2004a: Population-based public health interventions: practice-based and evidence-supported. Part I. Public Health Nursing 21, 453-68.

Keller, L.O., Strohschein, S., Schaffer, M.A. and Lia-Hoagberg, B. 2004b: Population-based public health interventions: innovations in practice, teaching, and management. Part II. Public Health Nursing 21, 469-87.

Kiefer, L., Frank, J., Di Ruggiero, E., Dobbins, M., Manuel, D., Gully, P.R. and Mowat, D. 2005: Fostering evidence-based

Primary Health Care Research \& Development 2007; 8: 170-182 
decision-making in Canada: examining the need for a Canadian population and public health evidence centre and research network. Canadian Journal of Public Health 96, 11-40 following 200.

Kluge, E.H. 1999: The Canadian health care system. An analytical perspective. Health Care Analysis (HCA) Journal of Health Philosophy and Policy 7, 377-91.

Kothari, A. and Edwards, N. 2003: Who is protecting the Canadian public health system? Home Health Care Management and Practice 15, 391-98.

Krueger, P., Brazil, K., Lohfeld, L., Edward, H.G., Lewis, D. and Tjam, E. 2002: Organization specific predictors of job satisfaction: findings from a Canadian multi-site quality of work life cross-sectional survey. BMC Health Services Research [computer file] 2, 6 .

Kuokkanen, L. and Katajisto, J. 2003: Promoting or impeding empowerment? Nurses' assessments of their work environment. The Journal of Nursing Administration 33, 209-15.

Kvale, S. 1996: Interviews: An introduction to qualitative research interviewing. Thousand Oaks, CA: Sage.

Lewis, S.J., Kouri, D., Estabrooks, C.A., Dickinson, H., Dutchak, J.J., Williams, J.I., Mustard, C. and Hurley, J. 2001: Devolution to democratic health authorities in Saskatchewan: an interim report. Canadian Medical Association Journal 164, 343-47.

Lincoln, Y.S. and Guba, E.G. 1985: Naturalistic inquiry. London: Sage.

MacDonald, M.B. and Schoenfeld, B.M. 2003: Expanding roles for public health nursing. The Canadian Nurse 99, 18.

May, K.M., Phillips, L.R., Ferketich, S.L. and Verran, J.A. 2003: Public health nursing: the generalist in a specialized environment. Public Health Nursing 20, 252-59.

McMurray, R. and Cheater, F. 2004: Vision, permission and action: a bottom up perspective on the management of public health nursing. Journal of Nursing Management 12, 43-50.

Meagher-Stewart, D. 2001: Public health nurses' community development practice with women in high-risk environments. Ph.D. thesis, University of Toronto.

Meagher-Stewart, D., Aston, M., Edwards, N., Smith, D., Woodford, E., and Young, L. 2004: Fostering citizen participation and collaborative practice: Tapping the voices and wisdom of public health nurses in Nova Scotia, Research Report. Halifax, NS: Dalhousie University.

Miles, M.B. and Huberman, A.M. 1994: Qualitative data analysis, second edition. Thousand Oaks, CA: Sage.

Moloughney, B. March/April 2005: Review of Nova Scotia's public health system-preliminary analysis of priorities and options-stakeholder discussions. Halifax, NS: Nova Scotia Department of Health and the Office of Health Promotion.

Moloughney, B. 2006: The renewal of public health in Nova Scotia: Building a public health system to meet the needs of Nova Scotians. Halifax, NS: Nova Scotia Health Promotion and Protection.

Naylor D. 2003: Learning from SARS: Renewal of public health in Canada. Ottawa, ON: National Advisory Committee on SARS. Health Canada.
Nova Scotia Department of Health. 1997: Nova Scotia health standards, first edition. Halifax, NS: Nova Scotia Department of Health.

Nova Scotia Department of Health. 2000: An act to provide for Community Health Boards and District Health Authorities and respecting provincial healthcare centres. Halifax, NS: Nova Scotia Department of Health.

Nova Scotia Department of Health. 2002: Task team on primary health care system funding and physician remuneration. Halifax, NS: Nova Scotia Department of Health.

Nova Scotia Department of Health. November 2005: Nova Scotia District Health Authorities 2001 post-censal population estimates for 2004. Halifax, NS: Nova Scotia Government.

Oberle, K. and Tenove, S. 2000: Ethical issues in public health nursing. Nursing Ethics 7, 425-38.

Patton, M. 2002: Quantitative research and evaluation methods, third edition. London: Sage.

Plews, C. Billingham, K. and Rowe, A. 2000: Public health nursing: barriers and opportunities. Health and Social Care in the Community 8, 138-146.

Rafael AF. 1999: From rhetoric to reality: the changing face of public health nursing in Southern Ontario. Public Health Nursing 16, 50-59.

Rafael, A.F. 2000: Nurses' orientations to change: debunking the 'resistant to change' myth. Journal of Professional Nursing: Official Journal of the American Association of Colleges of Nursing 16, 336-44.

Reutter, L.I. and Ford, J.S. 1998: Perceptions of changes in public health nursing practice: a Canadian perspective. International Journal of Nursing Studies 35, 85-94.

Rodger, G. and Gallagher, S. 2000: The move toward primary health care in Canada: Community health nursing from 1985-2000. In Stewart, M.J., editor, Community nursing: Promoting Canadians' health, second edition. Toronto, ON: WB Saunders, pp. 33-55.

Romanow, R. 2002: Building on values: The future of health care in Canada-Final report (the Romanow Report). Saskatoon, SK: Commission on the Future of Health Care in Canada.

Sandelowski, M. 1995: Focus on qualitative methods. Qualitative analysis: what it is and how to begin. Research in Nursing and Health 18, 371-75.

Schabas, R. 2002: Public health: what is to be done? Canadian Medical Association Journal 166, 1282-83.

Smith, D. 1987: The everyday world as problematic: $A$ feminist sociology: Toronto, ON: University of Toronto Press.

SmithBattle, L., Diekemper, M. and Drake, M. 1999: Articulating the culture and tradition of community health nursing. Public Health Nursing 16, 215-22.

Standing Senate Committee on Social Affairs, Science and Technology. 2003: Reforming health protection and promotion in Canada: Time to act (the Kirby Report). Ottawa, ON: The Senate of Canada.

Statistics Canada. 2005: Canadian statistics: Population by year, by provinces and territory. Ottawa, ON: Statistics Canada.

Primary Health Care Research \& Development 2007; 8: 170-182 


\section{Donna M. Meagher-Stewart et al.}

Retrieved from http://www40.statcan.ca/101/cst01/demo02. htm?sdi+population \%20year.

Sullivan, P. 2002: Canada's public health system beset by problems: report. Canadian Medical Association Journal 166,1319 .
Sutcliffe, P.A., Deber, R.B. and Pasut, G. 1997: Public health in Canada: a comparative study of six provinces. Canadian Journal of Public Health 88, 246-49.

Underwood, J. 2003: The value of nurses in the community. Ottawa, ON: Canadian Nurses Association. 